\title{
Effect of Metformin, Glibenclamide, Sitagliptin and their Combinations on Male Rats Fertility
}

\author{
Shiemaa Dafalla Alzain ${ }^{1, *}$, Mahmoud Mudawi Eltahir Mudawi ${ }^{1,2}$, Abdel Wahab Hasan Mohamed ${ }^{3}$, Mohd Imran $^{4}$, \\ Husham Mohammed Alhassan Attaalfadeel ${ }^{5,6}$ \\ 'Department of Pharmacology and Toxicology, Faculty of Pharmacy, Northern Border University, KINGDOM OF SAUDI ARABIA. \\ 2Department of Pharmacology, Faculty of Pharmacy, Omdurman Islamic University, Omdurman, SUDAN. \\ ${ }^{3}$ Department of Pharmacology, Faculty of Pharmacy, The National Rebat University, Khartoum, SUDAN. \\ ${ }^{4}$ Department of Pharmaceutical Chemistry, Faculty of Pharmacy, Northern Border University, KINGDOM OF SAUDI ARABIA. \\ 'Department of Economic, Faulty of Economic and Social Sciences, The Holy Quran University, Al Mourada Street, Omdurman, SUDAN. \\ ${ }^{6}$ Department of Mathematics, Faculty of Arts and Science, Rafha, Northern Border University, KINGDOM OF SAUDI ARABIA.
}

\begin{abstract}
Background: Diabetes Mellitus is a chronic metabolic disease characterized by hyperglycemia due to impaired insulin secretion or insulin resistance. It has been increasing at a high rate in the last decades, affecting males and females at reproductive age. Therefore, the current study aimed to assess the safety of some oral hypoglycemic drugs and their combinations on normal male rats' fertility. Methods: Ninety-six male rats were included in this experiment, and it consisted of two phases. The subchronic phase for 30 days and the chronic phase for 90 days. Each phase contained 48 rats, which were divided into 8 groups $(n=6)$ including the control group and the test groups (metformin $500 \mathrm{mg} / \mathrm{kg}$, glibenclamide $5 \mathrm{mg} / \mathrm{kg}$, sitagliptin 50 $\mathrm{mg} / \mathrm{kg}$, metformin $500 \mathrm{mg} / \mathrm{kg}$ plus glibenclamide $5 \mathrm{mg} / \mathrm{kg}$, metformin 500 $\mathrm{mg} / \mathrm{kg}$ plus sitagliptin $50 \mathrm{mg} / \mathrm{kg}$, glibenclamide $5 \mathrm{mg} / \mathrm{kg}$ plus sitagliptin 50 $\mathrm{mg} / \mathrm{kg}$ and the last group was a combination of the three mentioned drugs). The drugs were administered orally. After the completion of the experiment period for both phases, hormonal analysis and sperm parameters were measured. Results: The results of the subchronic and chronic phases
\end{abstract}

revealed that metformin and sitagliptin and their combination affected hormonal and sperm parameters negatively as they reduced testosterone level, sperm count and sperm motility. In comparison, glibenclamide didn't show any significant effect. Conclusion: This study concludes that metformin exhibits testicular dysfunction. The results of the combination of metformin and glibenclamide in chronic use are encouraging because glibenclamide reduced the testicular dysfunction effect of metformin. Key words: Diabetes mellitus, Glibenclamide, Male fertility, Metformin, Sitagliptin, Oral hypoglycemic agents.

Correspondence

Mrs. Shiemaa Dafalla Alzain

Department of Pharmacology and Toxicology, Faculty of Pharmacy, Northern Border University, KINGDOM OF SAUDI ARABIA.

Email: shaimaa.dafullah@nbu.edu.sa

DOI: 10.5530/jyp.2021.13.26

\section{INTRODUCTION}

Diabetes Mellitus (DM), a metabolic disease, is characterized by hyperglycemia, ${ }^{1}$ it has many classes, including type 1 , type 2 and gestational diabetes. ${ }^{2}$ The vast majority of diabetic patients are classified into one of two broad categories: type $1 \mathrm{DM}$ (T1DM), which is caused by an absolute or near absolute deficiency of insulin or type 2 DM (T2DM), which is caused by the presence of insulin resistance with an inadequate compensatory increase in insulin secretion. ${ }^{3}$ T1DM presents in children or adolescents, while T2DM is thought to affect middle-aged and older adults who have prolonged hyperglycemia due to poor lifestyle and dietary choices. ${ }^{2}$ The pathogenesis for T1DM and T2DM is drastically different, and therefore each type has various etiologies, presentations, and treatments. The chronic complications of diabetes mellitus comprise dysfunctions and failures of various organs, ${ }^{4}$ which can be divided into microvascular (nephropathy, neuropathy, and retinopathy) and macrovascular (stroke, cardiovascular disease, and peripheral artery disease). ${ }^{5}$ One of DM's complications is the disturbance in the male reproductive system, as glucose metabolism is an important event in spermatogenesis. ${ }^{4}$

Regarding diabetes treatment, insulin is vital for treating T1DM patients because there is a decrease in insulin release. However, treatment of T2DM patients is more complex because there is a defect in both insulin secretion and action. Therefore, the treatment selection will depend on the stage of the DM and the individual characteristics of the patient. ${ }^{6}$ The oral hypoglycemic agents for treating T2DM include biguanides (for example metformin), ${ }^{7}$ sulfonylureas (glibenclamide). ${ }^{8}$ Metformin and glibenclamide are considered to be the most widely used oral hypoglycemic agents because they are economical and mono-dosing. ${ }^{9}$ Another class of oral hypoglycemic drug is the thiazolidinedione's (for example pioglitazone), ${ }^{10}$ the dipeptidyl peptidase (DPP)-4 inhibitors (for example sitagliptin), ${ }^{11}$ and Glucagon-like peptide-1 (GLP-1) agonists 1 (for example exenatide). ${ }^{12}$ According to the American Diabetes Association, metformin is the preferred first-line therapy for the treatment of T2DM. However, the addition of a GLP-1 analog should be considered in patients with a contraindication or intolerance to metformin, in patients with a hemoglobin A1c greater than $1.5 \%$ over target, or in patients who do not reach their target Alc in three months, ${ }^{12}$ insulin therapy is frequently needed in the late stage of type 2 diabetes because of progressive $\beta$-cell dysfunction. ${ }^{13}$

Infertility is a distressing issue to both the couple and their families. Recognizing its importance, the World Health Organization has classified it as a global health problem. ${ }^{14}$ It is reported that about $15 \%$ of all couples trying to conceive during the first year of unprotected sex are affected by infertility. ${ }^{15}$ However, male factor infertility is responsible for about $20 \%$ of infertile couples. ${ }^{16}$ 
DM has been increasing in male patients at childbearing age, and its prevalence is linked with a decrease in fertility, a reduction in sperm motility. ${ }^{17}$ Moreover, DM affects almost all the male reproductive system levels, like testicular function and spermatogenesis. ${ }^{18}$ One study has provided a report that metformin may restore male reproductive function. However, it also states that it may lead to counterproductive effects and may affect the development of the fetus's testis during pregnancy. ${ }^{19}$ Similarly, sulfonylureas are also reported to have spermicidal as well as a protective effect on male fertility. ${ }^{20}$ Also, pioglitazone has shown a beneficial impact on the male reproductive system, including some sperm parameters due to its antioxidant properties. ${ }^{19}$ The DPP4 inhibitors like sitagliptin have to be used cautiously by diabetic males since it negatively impacts male fertility. ${ }^{21}$

Since diabetes is more prevalent nowadays and frequently being encountered in young and child-giving ages, this means that these patients will use anti-diabetic medications early-on in their lives, and for the time they expect to have their offspring's. These people would be thus most prone to be affected by side-effects of these medications. Therefore, this study aimed to evaluate some oral anti-diabetic drugs effects on the levels of sex hormones and sperm parameters of normal male rats.

\section{MATERIALS AND METHODS}

\section{Drugs}

Gift samples of working standards were obtained from Jamjoom Pharma. KSA (Metformin) and Amipharma Laboratories, Sudan (Glibenclamide and Sitagliptin).

\section{Animals}

Mature male Albino Wistar rats weighing between 180 and $250 \mathrm{~g}$ obtained from King Saud University, Kingdom of Saudi Arabia, were used in this study. The rats were kept in cages at room temperature; food and water were given ad libitum. Ethical approval was obtained from the biomedical ethics research committee of medical college, University of King Abdul-Aziz, Jeddah (Approval Ref. No. 689-2019).

\section{Experimental Design}

The experiment combined two phases: Sub-Chronic and Chronic drug administrations. And for all, the same Experimental protocol applied.

The rats in all groups were fed a regular chow diet and given the drug solution assigned for each group by oral gavage daily (throughout the Study). Then, after 30 days (for Sub-Chronic groups) or 90 days (for the chronic group) of treatment, several tests were performed according to the experimental protocol.

The male albino rats were assigned into eight groups $(n=6)$ :

Group (1) Control (received normal saline $10 \mathrm{ml} / \mathrm{kg}$ )

Group (2) received Metformin $500 \mathrm{mg} / \mathrm{kg}$

Group (3) received Glibenclamide $5 \mathrm{mg} / \mathrm{kg}$

Group (4) received Sitagliptin $50 \mathrm{mg} / \mathrm{kg}$

Group (5) received metformin $500 \mathrm{mg} / \mathrm{kg}+$ Glibenclamide $5 \mathrm{mg} / \mathrm{kg}$

Group (6) received metformin $500 \mathrm{mg} / \mathrm{kg}+$ Sitagliptin $50 \mathrm{mg} / \mathrm{kg}$

Group (7) received Glibenclamide $5 \mathrm{mg} / \mathrm{kg}+$ Sitagliptin $50 \mathrm{mg} / \mathrm{kg}$

Group (8) received Metformin $500 \mathrm{mg} / \mathrm{kg}+$ Glibenclamide $5 \mathrm{mg} / \mathrm{kg}+$ Sitagliptin $50 \mathrm{mg} / \mathrm{kg}$.

The animals were anaesthetized by diethyl ether, and $5 \mathrm{ml}$ blood samples were collected from abdominal aorta ${ }^{22}$ for hormonal analysis (testosterone, FSH and $\mathrm{LH}$ ). Then the animals were sacrificed, testis and cauda epididymis were isolated for sperm collection ${ }^{23}$ and histological study. Sperm was tested to see sperm count and sperm motility and semen PH. For testis histological test, $2-3 \mathrm{~mm}$ tissue was cut and fixed in $10 \%$ formalin. The tissues were processed and fixed by paraffin. Sections were stained with Haematoxylin and Eosin (H\&E) dye for microscopic observation.

\section{Statistical Analysis}

The data obtained were processed using IBM - SPSS (version 25), expressed as mean \pm SEM and analyzed using one-way ANOVA (LSD). The level of significance was taken as $p \leq 0.05$. GraphPad Prism 8 software was used for descriptive statistics.

\section{RESULTS}

\section{Sub-chronic Effects (30 days)}

As shown in Table 1; metformin administered for 30 days significantly $(P<0.05)$ decreased sperm count and testosterone level; however, it significantly $(P<0.05)$ increased LH and FSH levels when compared to the control group. Glibenclamide given for 30 days didn't considerably affect sperm count, testosterone level, LH and FSH level than the control group. Sitagliptin significantly $(P<0.05)$ decreased the sperm count and testosterone level while significantly $(P<0.05)$ increased LH and FSH levels when administered for 30 days compared to the control group. Figures 1-7

Also as shown in Table 1; the combination of Metformin plus Glibenclamide showed a significant decrease $(P<0.05)$ in sperm count

Table 1: Effect of metformin, glibenclamide, sitagliptin and their combinations administered for $\mathbf{3 0}$ days on the Sperm quality.

\begin{tabular}{|c|c|c|c|c|c|c|}
\hline $\begin{array}{l}\text { Parameter } \\
\text { Group }(n=6)\end{array}$ & $\begin{array}{c}\text { Sperm count } \\
\text { (cells\cubic millimetre) }\end{array}$ & Semen PH & $\begin{array}{c}\text { Sperm } \\
\text { motility (\%) }\end{array}$ & $\begin{array}{l}\text { Testosterone } \\
\text { (ngldl) }\end{array}$ & $\begin{array}{l}\text { LH } \\
\text { (IUIL) }\end{array}$ & $\begin{array}{l}\text { FSH } \\
\text { (IUIL) }\end{array}$ \\
\hline Control & $13500000.00 \pm 763762.62$ & $7.32 \pm 0.05$ & $64.17 \pm 3.24$ & $454.00 \pm 27.33$ & $1.79 \pm 0.18$ & $1.66 \pm 0.16$ \\
\hline Metformin & $7850000.00 \pm 601525.84^{\star}$ & $7.53 \pm 0.10$ & $56.50 \pm 4.14$ & $189.67 \pm 3.60^{*}$ & $3.77 \pm 0.16^{*}$ & $4.67 \pm 0.18^{\star}$ \\
\hline Glibenclamide & $12450000.00 \pm 636003.15$ & $7.32 \pm 0.09$ & $70.67 \pm 4.32$ & $442.17 \pm 16.99$ & $2.04 \pm 0.14$ & $1.75 \pm 0.14$ \\
\hline Sitagliptin & $7850000.00 \pm 1191567.60^{*}$ & $7.35 \pm 0.04$ & $54.33 \pm 3.34$ & $203.67 \pm 6.44^{\star}$ & $3.83 \pm 0.20^{\star}$ & $4.80 \pm 0.20^{*}$ \\
\hline Metformin + Glibenclamide & $10533333.33 \pm 449938.27^{\star}$ & $7.42 \pm 0.07$ & $73.00 \pm 2.18$ & $316.33 \pm 15.07^{\star}$ & $2.54 \pm 0.60$ & $2.48 \pm 0.52^{*}$ \\
\hline Metformin + Sitagliptin & $7166666.67 \pm 397212.51^{*}$ & $7.43 \pm 0.08$ & $70.50 \pm 2.74$ & $155.00 \pm 10.00^{*}$ & $5.50 \pm 0.20^{*}$ & $5.01 \pm 0.12^{*}$ \\
\hline Glibenclamide + Sitagliptin & $9033333.33 \pm 540781.33^{*}$ & $7.52 \pm 0.08$ & $65.67 \pm 4.30$ & $313.33 \pm 9.46^{*}$ & $2.48 \pm 0.18$ & $2.08 \pm 0.20$ \\
\hline $\begin{array}{c}\text { Metformin }+ \text { Glibenclamide }+ \\
\text { Sitagliptin }\end{array}$ & $8783333.33 \pm 340995.28$ * & $7.37 \pm 0.12$ & $66.83 \pm 2.95$ & $245.83 \pm 19.56^{*}$ & $3.87 \pm 0.23^{\star}$ & $2.87 \pm 0.20^{*}$ \\
\hline
\end{tabular}

$\mathrm{LH}=$ luteinizing hormone, FSH $=$ follicle stimulating hormones. Values are expressed as mean \pm SEM $(n=6) .{ }^{\star} P<0.05$ compared to the control group $($ ANOVA $)$ 
and testosterone level and caused substantial increase $(P<0.05)$ in FSH level compared to the control group. The administration of Metformin plus Sitagliptin caused a significant decrease $(P<0.05)$ in sperm count and testosterone level while causing a significant increase $(P<0.05)$ in LH and FSH level. Glibenclamide and Sitagliptin's combination produced only a significant decrease $(P<0.05)$ in sperm count and testosterone level. When Metformin, Glibenclamide and Sitagliptin were given together for 30 days, they produced significant reduction $(P<0.05)$ in sperm count and testosterone level while caused a significant increase $(P<0.05)$ in $\mathrm{LH}$ and FSH levels when compared to the control group.

However; all treatment groups showed no significant effects on semen $\mathrm{PH}$ and sperm motility.

sections in rat testis stained by H\&E to show seminiferous tubules and interstitial tissue and Leydig cells of: A (Group 1; Control), B (Group 2; Metformin), C (Group 3; Glibenclamide), D (Group 4; Sitagliptin), E (Group 5; Metformin+Glibenclamide), F (Group 6; Metformin+Sitagliptin), G (Group 7; Glibenclamide+Sitagliptin) and F (Group 8 Metformin+Sitagliptin+Glibenclamide) after 30 days.

Histological findings notice compared to normal-sized Seminiferous Tubules (ST) with their regular outlines, full-thickness germ cell layers (double arrows) and an average population of interstitial cells (white arrows) in Group 1: control (A); Group 2: (B) receiving metformin for four weeks showed sporadic deformed small-sized tubules with marked degeneration and loss of most germ cell layers (dotted arrows) others lack mature sperms, interstitial cells looked degenerated (white arrows). In Group 3: (C) glibenclamide most tubules looked normal with full germ cell layers and the presence of mature sperms (arrows). Group 4: (D) receiving Sitagliptin sporadic few tubules also showed degenerative changes (dotted arrows) compared to control, other tubules looked smaller and lack mature sperms. On the other hand, Group 5: (E) receiving Metformin+Glibenclamide showed preservation of seminiferous tubule's' normal structure (black arrows). Only a few tubules lack mature sperms, and interstitial cells are of the normal population. Group 6: (F) Metformin+Sitagliptin, there are few tubules showing loss of germ cell layers (dotted arrows). In Group 7: $(\mathrm{G})$ Glibenclamide+Sitagliptin there is loss few tubules demonstrated degenerative changes and loss of germ cell, others lack mature sperms. In Group 8: $(\mathrm{H})$ receiving the combination of metformin, glibenclamide and sitagliptin, there is the preservation of typical structure (black arrows). Still, many tubules showed partial loss of germ cells or lack mature sperms, and interstitial cells are of the normal population (white arrow).

\section{Chronic Effects (90 days)}

As shown in Table 2; metformin administered for 90 days significantly $(P<0.05)$ decreased sperm count, sperm motility and testosterone level; however, it significantly $(P<0.05)$ increased LH and FSH levels when compared to the control group. Glibenclamide given for 90 days didn't considerably affect sperm count, testosterone level, LH and FSH level than the control group. Sitagliptin significantly $(P<0.05)$ decreased sperm count, sperm motility and testosterone level while significantly $(P<0.05)$ increased LH and FSH levels when administered for 90 days compared to the control group. Figures 8-14.

Also as shown in Table 2; the combination of Metformin plus Glibenclamide showed a significant decrease $(P<0.05)$ in testosterone level and caused substantial increase $(P<0.05)$ in FSH level compared to the control group. The administration of Metformin plus Sitagliptin caused a significant decrease $(P<0.05)$ in sperm count and testosterone level while causing a significant increase $(P<0.05)$ in LH and FSH level. Glibenclamide and Sitagliptin's combination produced only a significant decrease $(P<0.05)$ in sperm count and testosterone level. When Metformin, Glibenclamide and Sitagliptin were given together for 90 days, they produced significant reduction $(P<0.05)$ in sperm count and testosterone level while caused a significant increase $(P<0.05)$ in LH and FSH levels when compared to the control group.

Sections in rat testis after 90 days of anti-diabetic drug administration compared to Group 1: (A) control group; showing that in Group 2: (B) received Metformin, more seminiferous tubules showed degenerative changes and loss of germ cell layers seminiferous. In Group 3: (C) administered glibenclamide, most tubules looked normal with full germ cell layers and presence of mature sperms (arrows), few tubules showed degenerative changes or lack of mature sperms (dotted squares). Group 4: (D) receiving Sitagliptin more sporadic few tubules also showed degenerative changes (dotted squares) compared to control, other tubules looked smaller and lack mature sperms. On the other hand, Group 5: (E) receiving Metformin+Glibenclamide showed the most seminiferous tubule's normal structure. However, some tubules still showed degenerative changes or lack mature sperms (dotted square), interstitial cells are of the normal population with little edematous interstitial spaces (white arrow). Group 6: (F) Metformin+Sitagliptin, there are few tubules showing loss of germ cell layers (dotted square). In Group 7: (G) Glibenclamide+Sitagliptin few tubules demonstrated degenerative changes and loss of germ cell (dotted squares) others looked normal and showed mature sperms, interstitial Leydig cells looked normal. In Group 8: $(\mathrm{H})$ receiving Combination of metformin, glibenclamide and sitagliptin there is marked preservation of ST normal structure (but few tubules showed lack of mature sperms (dotted arrows).

Table 2: Effect of Metformin, Glibenclamide, Sitagliptin and their combinations administered for $\mathbf{9 0}$ days on the Sperm quality.

\begin{tabular}{|c|c|c|c|c|c|c|}
\hline $\begin{array}{l}\text { Parameter } \\
\text { Group }(n=6)\end{array}$ & $\begin{array}{c}\text { Sperm count } \\
\text { (cells\cubic millimetre) }\end{array}$ & Semen PH & $\begin{array}{c}\text { Sperm motility } \\
(\%)\end{array}$ & $\begin{array}{l}\text { Testosterone } \\
\text { (ng\dl) }\end{array}$ & $\begin{array}{l}\text { LH } \\
\text { (IUIL) }\end{array}$ & $\begin{array}{l}\text { FSH } \\
\text { (IU\L) }\end{array}$ \\
\hline Control & $14166666.67 \pm 599258.80$ & $7.43 \pm 0.13$ & $63.33 \pm 5.05$ & $469.33 \pm 15.66$ & $1.87 \pm 0.17$ & $1.79 \pm 0.17$ \\
\hline Glibenclamide & $12710000.00 \pm 373407.73$ & $7.317 \pm 0.07$ & $69.50 \pm 4.11$ & $444.83 \pm 23.51$ & $2.09 \pm 0.12$ & $2.05 \pm 0.19$ \\
\hline Sitagliptin & $7376666.67 \pm 1328562.30^{*}$ & $7.53 \pm 0.08$ & $52.17 \pm 2.69^{*}$ & $226.67 \pm 17.22 *$ & $4.11 \pm 0.13^{*}$ & $5.08 \pm 0.16^{*}$ \\
\hline Glibenclamide + Sitagliptin & $6690000.00 \pm 1885444.25^{*}$ & $7.52 \pm .05$ & $66.00 \pm 3.89$ & $293.67 \pm 7.81^{\star}$ & $2.55 \pm 0.25$ & $1.95 \pm 0.14$ \\
\hline $\begin{array}{c}\text { Metformin + Glibenclamide + } \\
\text { Sitagliptin }\end{array}$ & $9850000.00 \pm 368555.74^{*}$ & $7.43 \pm 0.11$ & $64.00 \pm 2.60$ & $253.67 \pm 22.19 *$ & $4.13 \pm 0.17^{*}$ & $2.41 \pm 0.16^{*}$ \\
\hline
\end{tabular}

$\mathrm{LH}=$ luteinizing hormone, $\mathrm{FSH}=$ follicle stimulating hormones. Values are expressed as mean $\pm \mathrm{SEM}(n=6) .{ }^{*} P<0.05$ as compared to the control (ANOVA) 


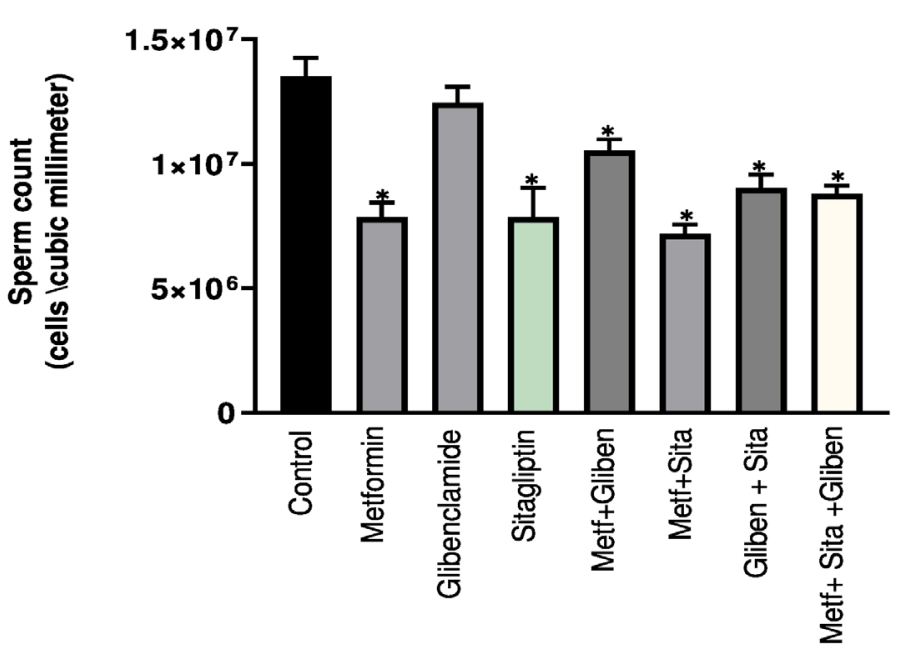

Figure 1 : Effect of Metformin (Metf), Glibenclamide (Gliben), Sitagliptin (sita) and their combinations administered for 30 days on the sperm counts in normoglycemic rats: $(n=6)$.

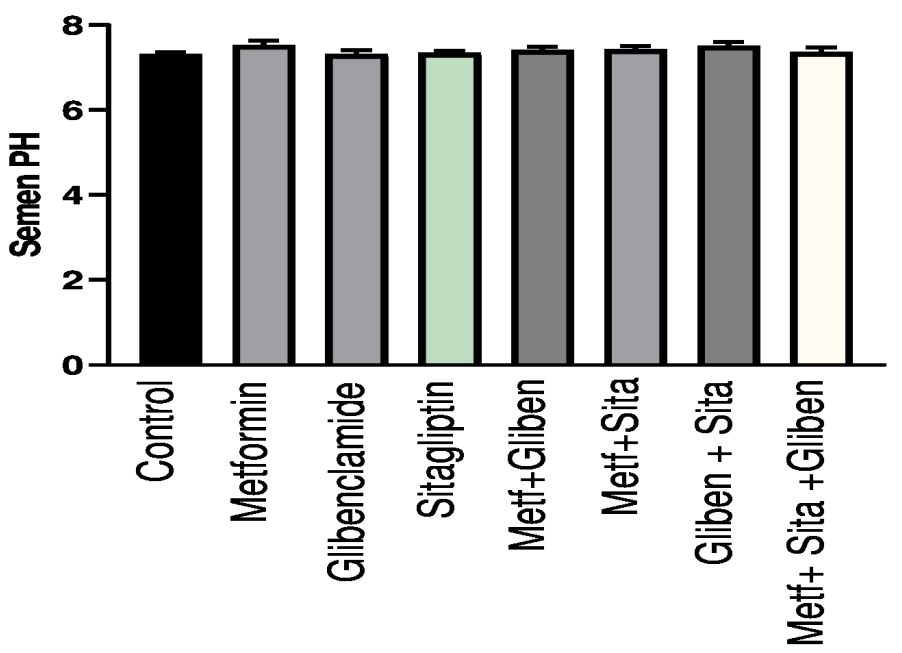

Figure 2 : Effect of Metformin (Metf), Glibenclamide (Gliben), Sitagliptin (sita) and their combinations administered for 30 days on semen $\mathrm{PH}$ in normoglycemic rats: $(n=6)$.

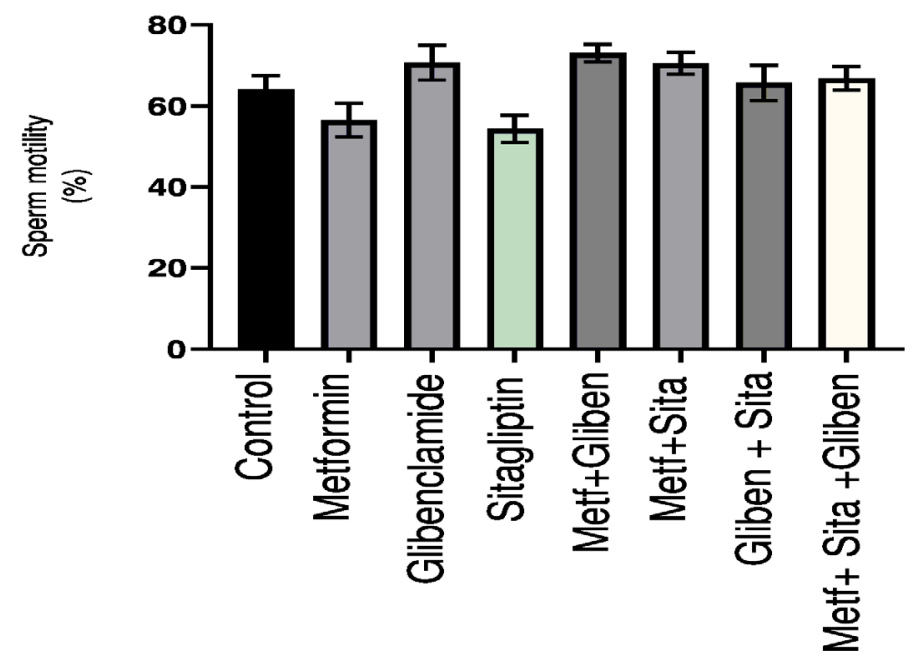

Figure 3 : Effect of Metformin (Metf), Glibenclamide (Gliben), Sitagliptin (sita) and their combinations administered for 30 days on the sperm motility in normoglycemic rats: $(n=6)$.

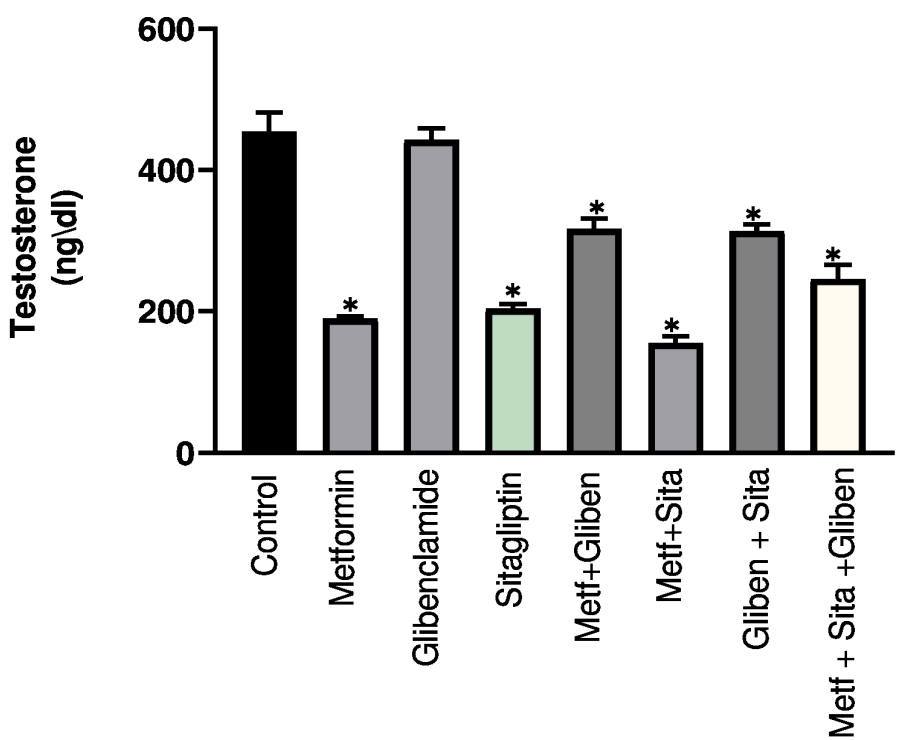

Figure 4 : Effect of Metformin (Metf), Glibenclamide (Gliben), Sitagliptin (sita) and their combinations administered for 30 days on testosterone level in normoglycemic rats: $(n=6)$.

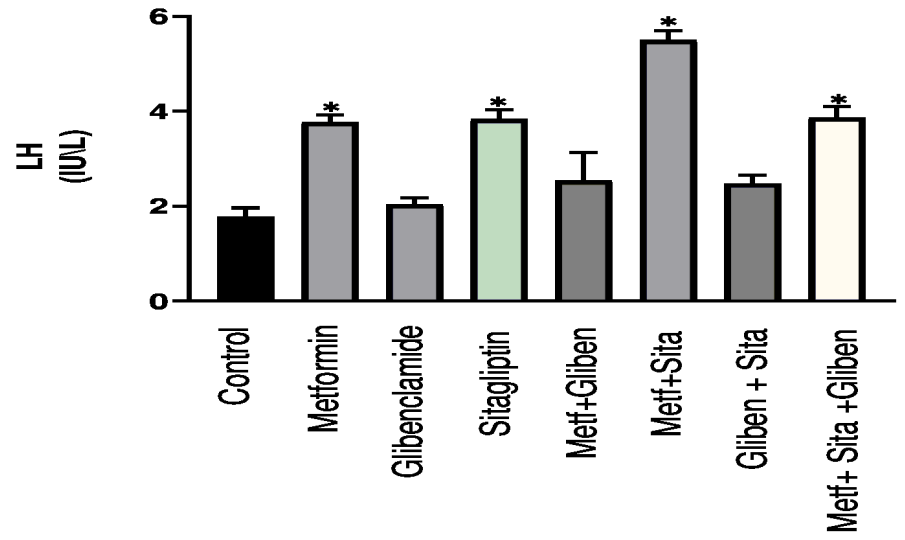

Figure 5 : Effect of Metformin (Metf), Glibenclamide (Gliben), Sitagliptin (sita) and their combinations administered for 30 days on LH level in normoglycemic rats: $(n=6)$.

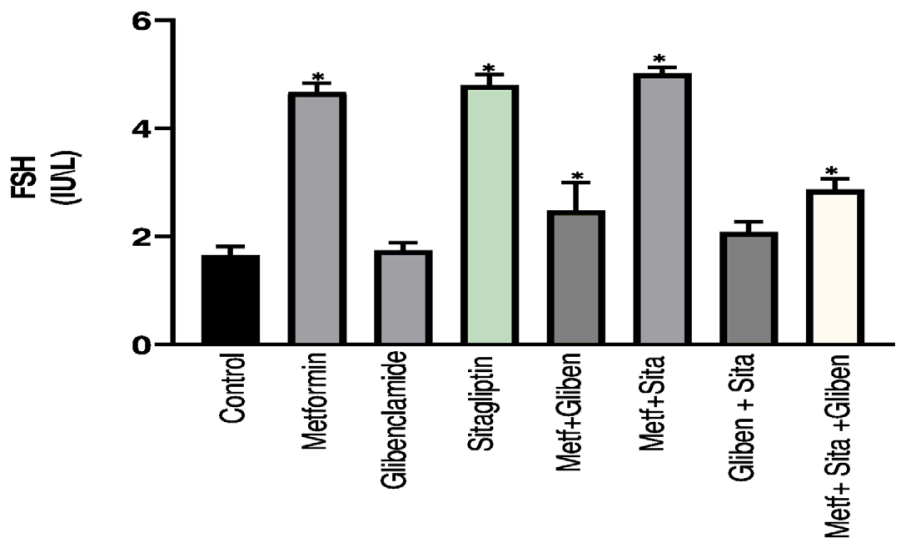

Figure 6 : Effect of Metformin, Glibenclamide (Gliben), Sitagliptin (sita) and their combinations administered for 30 days on FSH level in normoglycemic rats: $(n=6)$ 

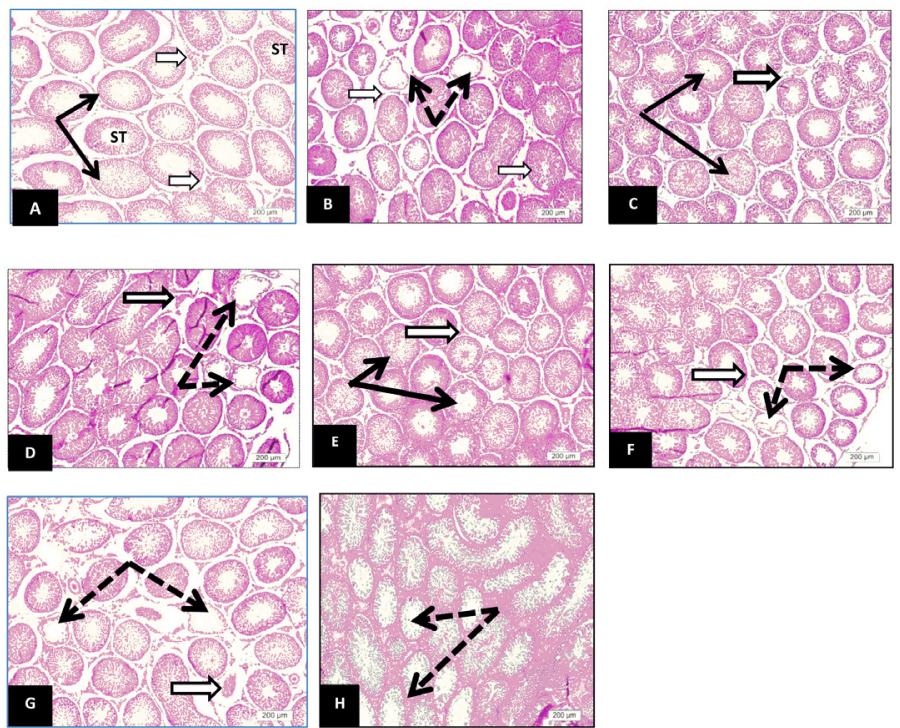

Figure 7 : Histological effect of metformin, glibenclamide, sitagliptin and their combinations administered for 30 days on rat testis.

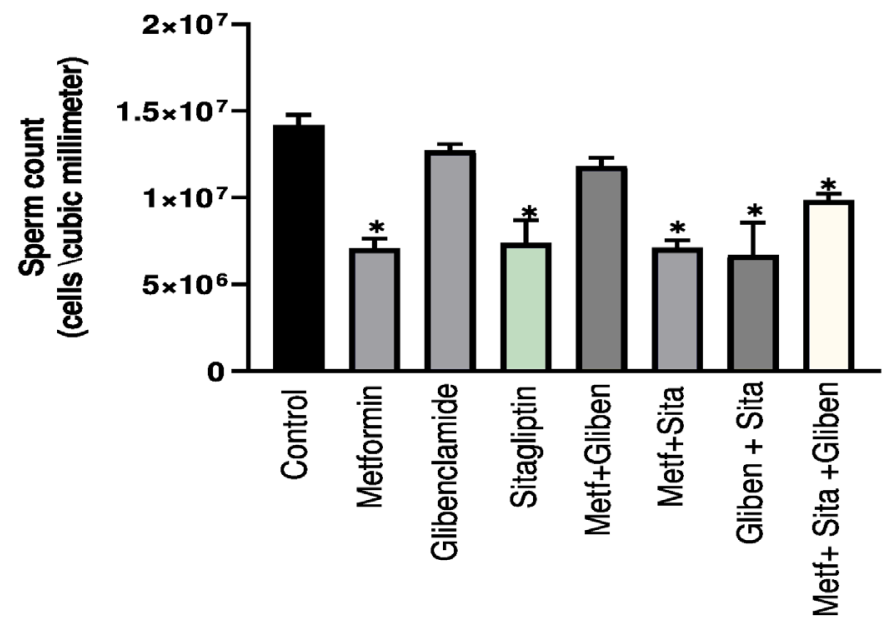

Figure 8 : Effect of Metformin (Metf), Glibenclamide (Gliben), Sitagliptin (sita) and their combinations administered for 90 days on the sperm counts in normoglycemic rats: $(n=6)$.

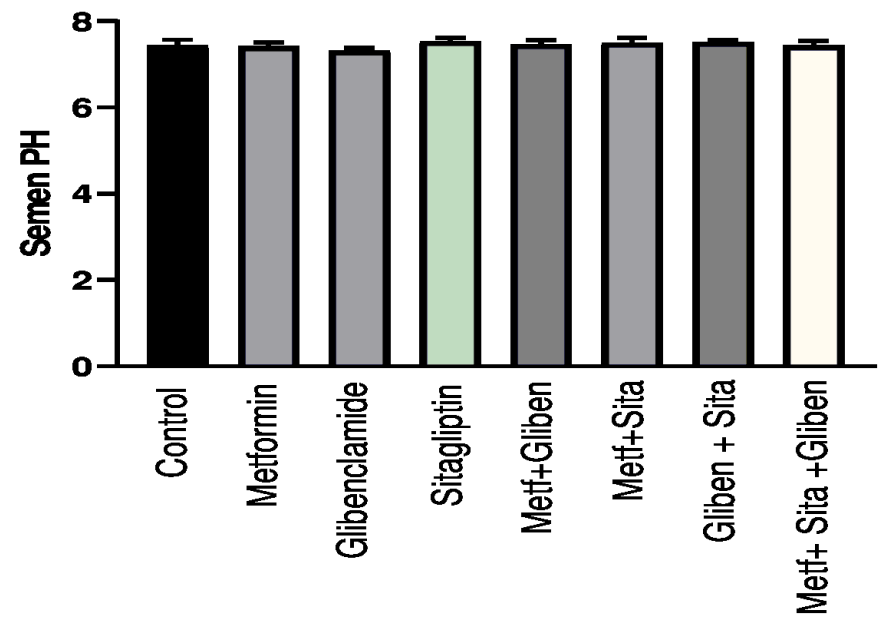

Figure 9 : Effect of Metformin (Metf), Glibenclamide (Gliben), Sitagliptin (sita) and their combinations administered for 90 days on semen $\mathrm{PH}$ in normoglycemic rats: $(n=6)$.

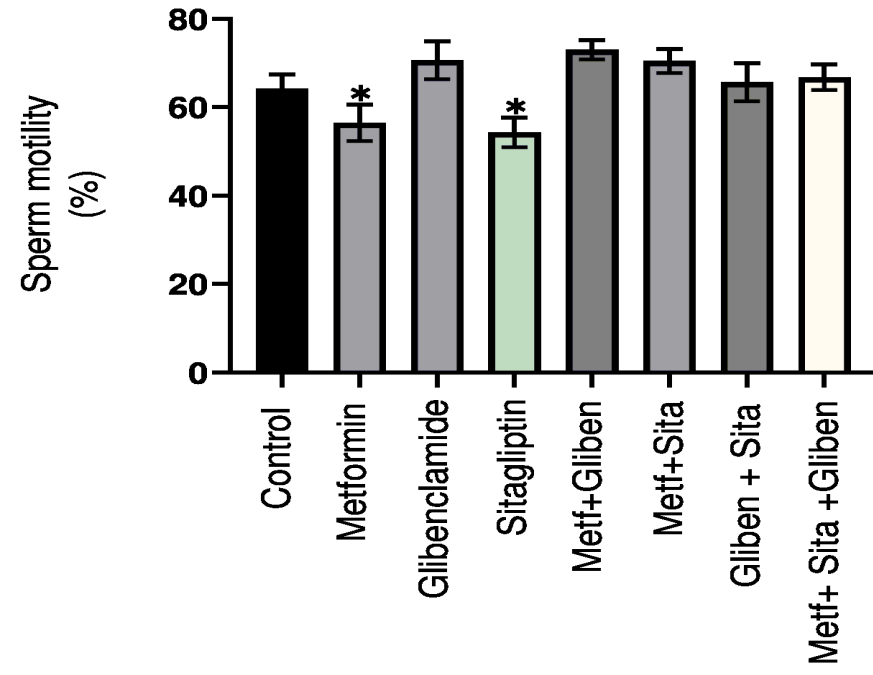

Figure 10 : Effect of Metformin (Metf), Glibenclamide (Gliben), Sitagliptin (sita) and their combinations administered for 90 days on serm motility in normoglycemic rats: $(n=6)$.

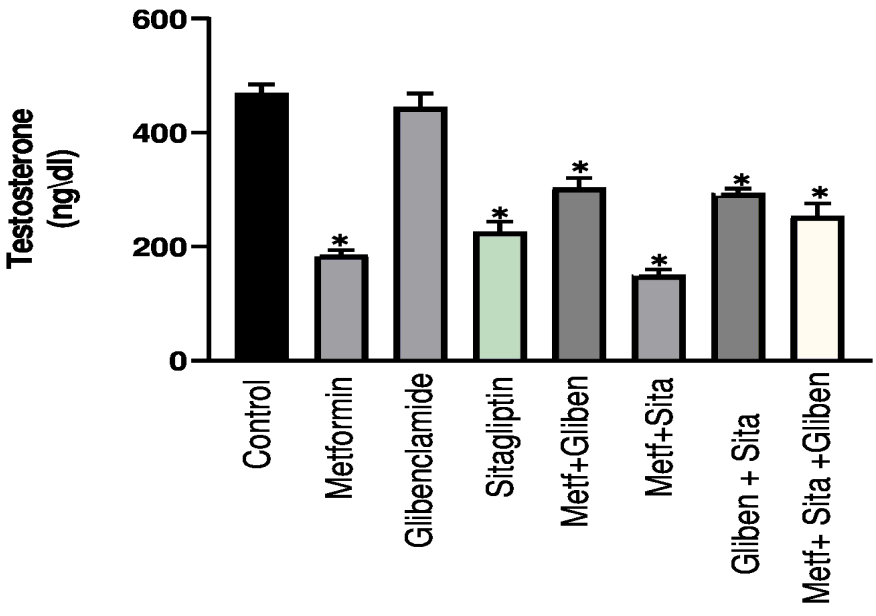

Figure 11 : Effect of Metformin (Metf), Glibenclamide (Gliben), Sitagliptin (sita) and their combinations administered for 90 days on testosterone level in normoglycemic rats: $(n=6)$.

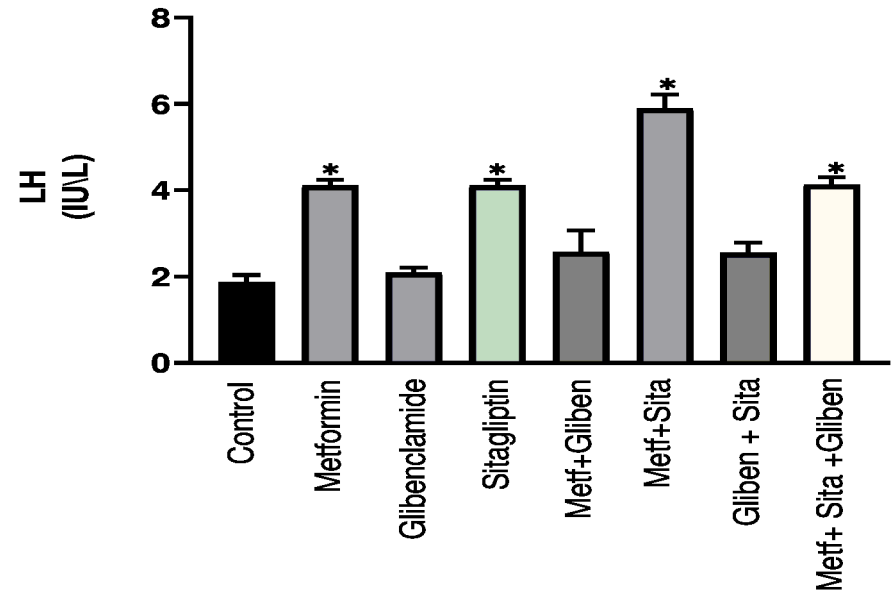

Figure 12 : Effect of Metformin (Metf), Glibenclamide (Gliben), Sitagliptin (sita) and their combinations administered for 90 days on LH level in normoglycemic rats: $(n=6)$. 


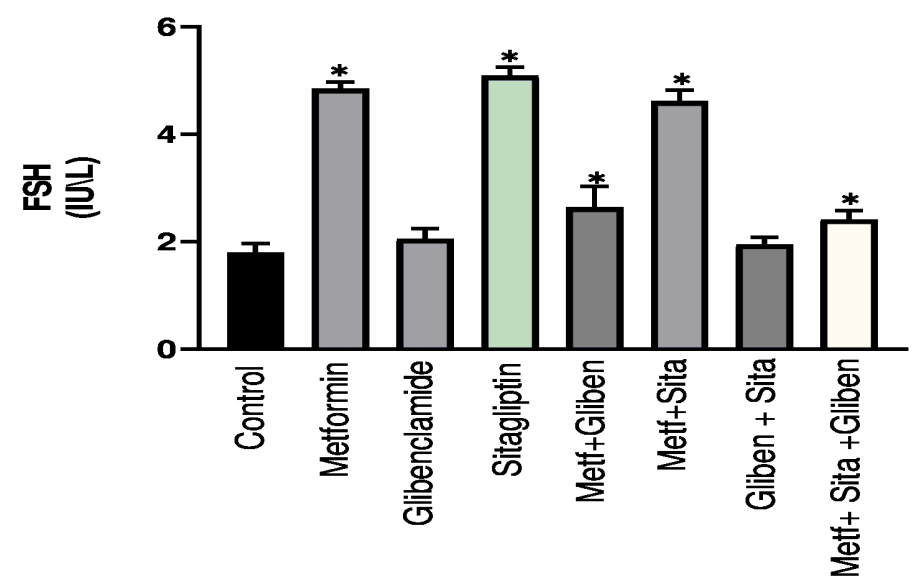

Figure 13 : Effect of Metformin (Metf), Glibenclamide (Gliben), Sitagliptin (sita) and their combinations administered for 90 days on FSH level in normoglycemic rats: $(n=6)$.
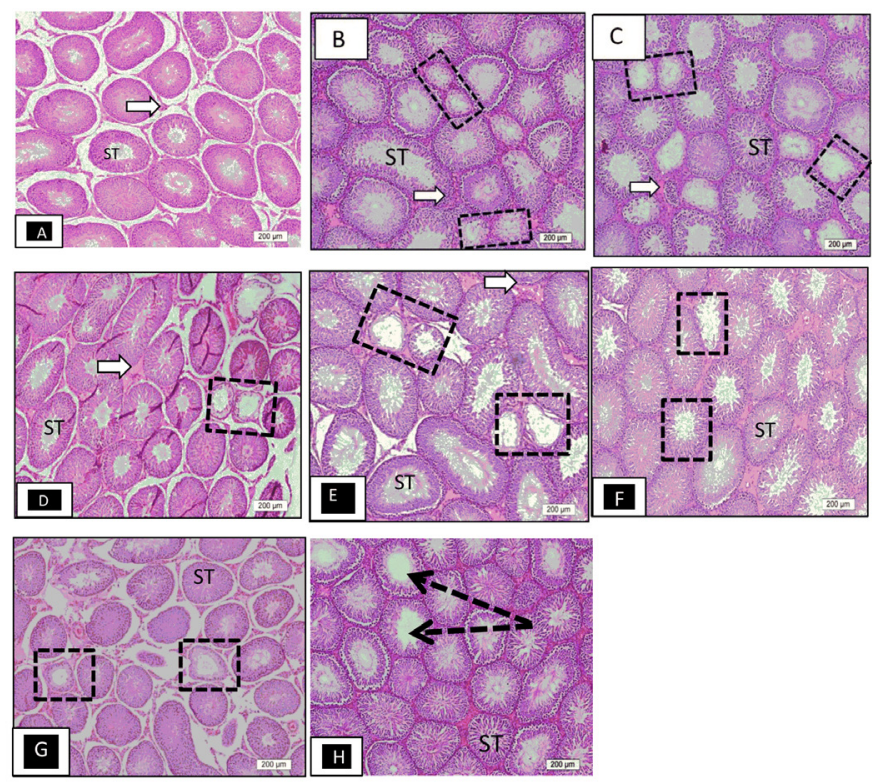

Figure 14 : Histological effect of metformin, glibenclamide, sitagliptin and their combinations administered for 90 days in rat testis.

\section{DISCUSSION}

Diabetes mellitus has been increasing at an alarming rate since the last decade. As it affects male and female in reproductive age, its complications, and the drugs used for lowering blood glucose level may affect human fertility. Accordingly, the current study was conducted to evaluate the effects of metformin, glibenclamide, sitagliptin and their combinations on male fertility in normoglycemic rats. This study was conducted in two phases: Sub-chronic phase and chronic drug administration phase. At the end of the experiment, hormonal and sperm parameters were measured.

Our results showed a significant decrease $(p<0.05)$ in sperm count and the testosterone level in the rats administered with metformin compared to the control group in sub-chronic and chronic phase. On the other hand, there is a significant elevation of LH and FSH level. It is reported that low testosterone levels and high-normal to high LH levels and FSH are associated with primary hypogonadism. ${ }^{24} \mathrm{~A}$ decrease in testosterone secretion, sex drive and testosterone-induced erectile dysfunction has also been reported in prior reports. ${ }^{25,26} \mathrm{~A}$ combination of hypocaloric diet and metformin has also resulted in a low level of the circulating testosterone levels in obese non-diabetic men. ${ }^{27}$ In healthy male rats, metformin decreases testosterone levels. ${ }^{26}$ However, the same study also states that metformin restores testosterone secretion in diabetic rats to levels near those seen on healthy individuals. ${ }^{28}$ Metformin also significantly decreased the sperm motility in the chronic phase. This observation agrees with the other study, which concluded that metformin significantly reduced the percentage of motile, progressive and rapid spermatozoa and significantly decreased sperm velocity. ${ }^{29}$ Another study found that metformin negatively affected sperm count and sperm motility in the non-diabetic normal control group. ${ }^{30}$ Another research has revealed a slight reduction in sperm motility at $5000 \mathrm{lM}$ metformin. ${ }^{31}$ Our study suggests that the decrease in sperm motility is associated with the duration of metformin treatment. Literature also states that in utero exposure to metformin reduces fetal testicular size and Sertoli cell populations (SC). These processes may be driven by the metforminmediated increase in lactate production, decreasing testosterone secretion. ${ }^{32}$ One study states that metformin can be considered as a suitable anti-diabetic drug for male patients of reproductive age ${ }^{33}$ which is contradictory to our results. However, this study says that this contradiction may be due to the difference in the experimental protocol in which they used isolated Sertoli cells cultured with high glucose level. ${ }^{33}$ Another study aimed at exploring the effects of metformin and characterizing its underlying mechanism in the fertility of obese males concluded that metformin increases FSH level. It improves obese male fertility by alleviating oxidative stress-induced blood-testis barrier damage. ${ }^{34}$ Hagar A Hashish et al. stated that metformin-induced changes in pancreatic and testicular tissues, testicular tissue in metformin-treated rats the Seminiferous Tubules (STs) were irregular in outline, disturbed organization of germinal epithelium, spermatogenic cells were separated from basement membrane with signs of degeneration, and the diameter of STs was significantly reduced. ${ }^{35}$ Another study showed marked necrosis, degeneration of seminiferous tubules, and spermatocyte's defoliation in the testis of MET-treated rats. ${ }^{36}$ Carolina et al. reported that metformin reduces testosterone production and also cause significant reduction in sperm motility and sperm count in male rats, which might be due to ageneral decrease in the rat's antioxidant status testis due to administration of metformin. ${ }^{37}$ Ribeiro et al. concluded that metformin has a protective effect on metabolically ill patient's productive function while it has a harmful impact on healthy subjects. ${ }^{38}$

In our study, glibenclamide alone didn't significantly affect any hormonal or sperm parameter. However, when combined with metformin in the chronic phase, the sperm count was observed at a normal level compared to the metformin group alone. The prior study has revealed decreased sperm count and motility with the individual treatment of metformin and glibenclamide. ${ }^{36}$ This previous study has also presumed that a combination of metformin and glibenclamide may cause testicular dysfunction. This is interesting to mention that our study provided opposite results to this presumption. Our findings also suggest that glibenclamide might be preventing the testicular dysfunction effect of metformin in the chronic group. However, this effect was not observed in the subchronic group. Therefore, we believe that glibenclamide can prevent metformin's testicular dysfunction if used for a more extended period. This effect is relevant to one study that concluded that glibenclamide has a protective effect against nuclear damage caused by diabetes, enhancing the antioxidant status and decreasing sperm abnormality. ${ }^{39}$

In the current study, sitagliptin alone or in combination with metformin and glibenclamide in both subchronic and chronic phase affected sperm count and testosterone level negatively. Simultaneously, it increased the level of LH and FSH, which represent signs of primary hypogonadism. Our results agree with other studies, which reported a decrease in semen motility and free testosterone levels in the serum. ${ }^{18,40}$ A study published in 2020 stated that testis of rats given Sitagliptin show marked destruction 
of many Seminiferous Tubules (S.Ts), damage of their lining germinal epithelium and vacuolation of its cytoplasm and marked reduction in the number of sperms in the lumen, interstitial Leydig cell show degenerative changes. ${ }^{40}$ However; Sitagliptin is reported to have an antioxidative effect, and it also reversed the testicular ischemia/reperfusion damage in male rats. ${ }^{41}$ It is also reported to restore testosterone's average level in doxorubicin-induced testicular damage when used in combination with quercetin (an antioxidant). ${ }^{42}$

\section{CONCLUSION}

This study concludes that metformin exhibits testicular dysfunction. The results of the combination of metformin and glibenclamide in chronic use are encouraging. It is assumed that glibenclamide prevents the testicular dysfunction effects of metformin by its antioxidative effect. The combination of metformin, glibenclamide and sitagliptin did not produce encouraging results like the combination of glibenclamide and metformin. Further studies for the combination of metformin, glibenclamide and sitagliptin is recommended in diabetic rats.

\section{ACKNOWLEDGEMENT}

The authors would like to thank Mansour Scientific Foundation for providing facilities for carrying out this work.

\section{CONFLICT OF INTEREST}

The authors declare no conflict of interest.

\section{ABBREVIATIONS}

T1DM: type 1 diabetes mellitus; T2DM: type 2 diabetes mellitus; DDP: dipeptidyl peptidase; GLP: glucagon like peptide; Sc: sertoli cells; STs: seminiferous tubules.

\section{REFERENCES}

1. American Diabetes Association. Diagnosis and classification of diabetes mellitus. Diabetes Care. 2013;36(Suppl 1):S67-74.

2. Sapra A, Bhandari P. Diabetes Mellitus. StatPearls. Treasure Island (FL): StatPearls Publishing Copyright (C) 2021, StatPearls Publishing LLC.; 2021.

3. Solis-Herrera C, Triplitt C, Reasner C, DeFronzo RA, Cersosimo E. Classification of diabetes mellitus. Endotext [Internet]. 2018.

4. Ding GL, LiuY, Liu ME, Pan JX, Guo MX, Sheng JZ, et al. The effects of diabetes on male fertility and epigenetic regulation during spermatogenesis. Asian $\mathrm{J}$ Androl. 2015;17(6):948.

5. Deshpande AD, Harris-Hayes M, Schootman M. Epidemiology of diabetes and diabetes-related complications. Physical therapy. 2008;88(11):1254-64

6. Simó R, Hernández C. Treatment of diabetes mellitus: general goals, and clinical practice management. Rev Esp Cardiol. 2002;55(8):845-60.

7. Blaslov K, Naranđa FS, Kruljac I, Renar IP. Treatment approach to type 2 diabetes: Past, present and future. World J Diabetes. 2018;9(12):209.

8. Rambiritch $V$, Maharaj B, Naidoo P. Glibenclamide in patients with poorly controlled type 2 diabetes: A 12-week, prospective, single-center, open-label, dose-escalation study. Clinical Pharmacology: Advances and Applications. 2014;6:63

9. Sola D, Rossi L, Schianca GPC, Maffioli P, Bigliocca M, Mella R, etal. Sulfonylureas and their use in clinical practice. Arch Med Sci: AMS. 2015;11(4):840.

10. He L, Liu X, Wang L, Yang Z. Thiazolidinediones for nonalcoholic steatohepatitis: A meta-analysis of randomized clinical trials. Medicine. 2016;95(42);e4947.

11. Moore KB, Saudek CD. Therapeutic potential of dipeptidyl peptidase-IV inhibitors in patients with diabetes mellitus. Am J Ther. 2008;15(5):484-91.

12. Collins L, Costello RA. Glucagon-like Peptide-1 Receptor Agonists. StatPearls. 2019.

13. Jabbour M. Primary care physicians and insulin initiation: Multiple barriers, lack of knowledge or both?. International Journal of Clinical Practice. 2008;62(6):845-7.

14. George K, Kamath MS. Fertility and age. J Hum Reprod Sci. 2010;3(3):121-3.

15. Sansone A, Di Dato C, de Angelis C, Menafra D, Pozza C, Pivonello R, et al. Smoke, alcohol and drug addiction and male fertility. Reprod Biol Endocrinol. 2018;16(1):3.
16. Sharlip ID, Jarow JP, Belker AM, Lipshultz LI, Sigman M, Thomas AJ, et al. Best practice policies for male infertility. Fertil Steril. 2002;77(5):873-82.

17. Condorelli RA, La Vignera S, Mongiò̀ LM, Alamo A, Calogero AE. Diabetes Mellitus and Infertility: Different Pathophysiological Effects in Type 1 and Type 2 on Sperm Function. Front Endocrinol. 2018:9:268.

18. Tavares RS, Escada-Rebelo S, Silva AF, Sousa MI, Ramalho-Santos J, Amaral S Antidiabetic therapies and male reproductive function: where do we stand? Reproduction. 2018;155(1):R13-37.

19. Tavares RS, Escada-Rebelo S, Sousa MI, Silva A, Ramalho-Santos J, Amaral S. Can Antidiabetic Drugs Improve Male Reproductive (Dys) Function Associated with Diabetes?. Cur Med Chem. 2019:26(22):4191-222.

20. Kumar N, Jain S, Gupta A, Tiwary AK. Spermicidal activity of sulfonylureas and meglitinide analogues: Role of intrasperm Ca2+ elevation. J Pharm Pharmacol. 2008;60(3):323-30.

21. Fontoura $P$, Cardoso MC, Erthal-Martins MC, Werneck C, Sartorio C, Ramos CF. The effects of liraglutide on male fertility: A case report. Reproductive biomedicine online. 2014;29(5):644-6.

22. Parasuraman $S$, Raveendran $R$, Kesavan $R$. Blood sample collection in small laboratory animals. J Pharmacol Pharmacother. 2010;1(2):87-93.

23. Luthfi MJF. A simple and practical method for rat epididymal sperm count (Rattus norvegicus). Biol Med Natural Product Chem. 2015;4(1):1-3.

24. Carnegie C. Diagnosis of hypogonadism: Clinical assessments and laboratory tests. Reviews in Urology. 2004;6(Suppl 6):S3-8.

25. Tartarin P, Moison D, Guibert E, Dupont J, Habert R, Rouiller-Fabre V, et al. Metformin exposure affects human and mouse fetal testicular cells. Human Reproduction. 2012;27(11):3304-14.

26. Al-Kuraishy HM, Al-Gareeb Al. Erectile Dysfunction and Low Sex Drive in Men with Type 2 DM: The Potential Role of Diabetic Pharmacotherapy. J Clin Diagn Res. 2016;10(12):Fc21-6.

27. Ozata M, Oktenli C, Bingol N, Ozdemir IC. The effects of metformin and diet on plasma testosterone and leptin levels in obese men. Obesity Research. $2001 ; 9(11): 662-7$.

28. Ribeiro JC, Alves MG, Oliveira PF. The Antidiabetic Drug Metformin and Male Fertility: An Update. Int J Diabetol Vasc Dis Res. 2019;7(1e):1-3.

29. Calle-Guisado V, Gonzalez-Fernandez L, Martin-Hidalgo D, Garcia-Marin L, Bragado M. Metformin inhibits human spermatozoa motility and signalling pathways mediated by protein kinase $A$ and tyrosine phosphorylation without affecting mitochondrial function. Reprod Fertil Dev. 2019;31(4):787-95.

30. Fang X, Xu QY, Jia C, Peng YF. Metformin improves epididymal sperm quality and antioxidant function of the testis in diet-induced obesity rats. Zhonghua nan ke $x$ ue $=$ National J Androl. 2012;18(2):146-9

31. Bertoldo MJ, Guibert E, Tartarin P, Guillory V, Froment P. Effect of metformin on the fertilizing ability of mouse spermatozoa. Cryobiology. 2014;68(2):262-8.

32. Faure M, Bertoldo MJ, Khoueiry R, Bongrani A, Brion F, Giulivi $C$, et al. Metformin in reproductive biology. Front Endocrinol. 2018;9:675.

33. Alves MG, Martins AD, Vaz CV, Correia S, Moreira PI, Oliveira PF, et al. Metformin and male reproduction: Effects on Sertoli cell metabolism. Br J Pharmacol. 2014;171(4):1033-42

34. Ye J, Luo D, Xu X, Sun M, Su X, Tian Z, et al. Metformin Improves Fertility in Obese Males by Alleviating Oxidative Stress-Induced Blood-Testis Barrier Damage. Oxi Med Cell Longev. 2019;2019:9151067.

35. Hashish HA. Effect of metformin on Bax expression in pancreas and testis of normoglycemic albino rat: An immunohistochemical study. Indian J Clin Anat Physiol. 2020;7(2):134-41.

36. Adaramoye O, Akanni O, Adesanoye O, Labo-Popoola O, Olaremi O. Evaluation of toxic effects of metformin hydrochloride and glibenclamide on some organs of male rats. Niger J Physiol Sci. 2012;27(2):137-44.

37. Ferreira C, Sousa M, Rabaça A, Oliveira PF, Alves MG, Sá R. Impact of Metformin on Male Reproduction. Curr Pharm Des. 2015;21(25):3621-33.

38. Ribeiro JC, Alves MG, Oliveira PF. Uso da metformina no tratamento de doenças metabólicas e da saúde reprodutiva masculina. Acta Farmacêutica Portuguesa. 2020;9(1):3-14

39. Rabbani SI, Devi K, Khanam S. Protective role of glibenclamide against nicotinamide-streptozotocin induced nuclear damage in diabetic Wistar rats. J Pharmacol Pharmacother. 2010;1(1):18.

40. Yassien RI, Ghoneim NS. Comparative Histological and Immunohistochemical Study on the Effects of Antidiabetic Drugs (Metformin versus Sitagliptin) on the Testes of Adult Male Albino Rat. Egyptian J Histol. 2020;43(1):353-72.

41. Abdel-Aziz AM, Hafez NASM. Sitagliptin protects male albino rats with testicular ischaemia/reperfusion damage: Modulation of VCAM-1 and VEGF-A. Andrologia. 2020;52(2):e13472

42. Ahmed ZA, Abtar AN, Othman HH, Aziz TA. Effects of quercetin, sitagliptin alone or in combination in testicular toxicity induced by doxorubicin in rats. Drug Des Devel Ther. 2019;13:3321. 